\title{
THE ROLE OF REMITTANCES ON POVERTY REDUCTION: AN EMPIRICAL ANALYSIS ON DEVELOPING COUNTRIES*
}

DOI: 10.17261/Pressacademia.2020.1308

JEFA- V.7-ISS.4-2020(5)-p.346-354

\section{Gulbahar Ucler ${ }^{1}$, Serife Ozsahin ${ }^{2}$}

${ }^{1}$ Kırşehir Ahi Evran University, Faculty of Economics and Administrative Sciences, Department of Economics, Kirsehir, Turkey. gulbahar.ucler@ahievran.edu.tr, ORCID: 0000-0002-5872-8577

${ }^{2}$ Necmettin Erbakan University, Faculty of Political Sciences, Department of Economics, Konya, Turkey.

sozsahin@erbakan.edu.tr, ORCID: 0000-0001-8310-1816

Date Received: September 25, 2020

Date Accepted: November 25, 2020

To cite this document

Ucler, G., Ozsahin, S., (2020). The role of remittances on poverty reduction: an empirical analysis on developing countries. Journal of Economics, Finance and Accounting (JEFA), V.7(4), p.346-354.

Permemant link to this document: $\underline{\text { htp://doi.org/10.17261/Pressacademia.2020.1308 }}$

Copyright: Published by PressAcademia and limited licenced re-use rights only.

\section{ABSTRACT}

Purpose - This study aims to analyze the impact of remittances on poverty in the largest remittance-receiving 10 developing countries in 2019 in the light of World Bank data.

Methodology - Due to lack of data and insufficient observations, this study employed static panel methods including pooled OLS, fixed effect and random effect estimations.

Findings- Empirical findings obtained in the study show that remittances have statistically significant and negative effects on all poverty measures considered. In addition, while the increase in per capita income in the long run has poverty-reducing effects, the rise in inflation rates deepens poverty.

Conclusion- With the increase in global migration movements, the importance of remittances in the socio-economic development of countries is increasing. For this reason, it is important that countries receiving remittances develop well-considered policies to manage remittances correctly.

Keywords: International migration, remittances, poverty, developing countries, pooled OLS.

JEL Codes: F22, F24, P46

\section{YOKSULLUĞUN AZALTILMASINDA işÇi DÖVIZLERININ ROLÜ: GELIŞMEKTE OLAN ÜLKELER ÜZERINE AMPIRIK BIR ANALIZ}

\section{ÖZET}

Amaç - Bu çalışmanın amacı, Dünya Bankası verilerine göre 2019 yılında en fazla göçmen gönderisi alan 10 gelişmekte olan ülkede göçmen gönderilerinin yoksulluk üzerindeki etkisini incelemektir.

Yöntem - Değişkenlere ait verilerin kesikli olması ve gözlem sayısının düşüklüğü nedeniyle statik panel yöntemlerinden havuzlanmış EKK, sabit etkiler ve rassal etkiler modeli ile tahmin yapılmıştır.

Bulgular- Çalışmadan elde edilen ampirik bulgulara göre, göçmen gönderileri tüm yoksulluk endeksleri üzerinde negatif yönlü ve anlamlı etkiye sahiptir. Ayrıca uzun dönemde kişi başı gelir düzeyinde artış yoksulluğu azaltıcı etkilere sahipken enflasyon oranlarındaki yükseliş, yoksulluğu derinleştirmektedir.

Sonuç- Küresel göç hareketlerinin artmasıyla birlikte ülkelerin sosyo-ekonomik kalkınmasında işçi dövizlerinin önemi artmaktadır. Bu nedenle, işçi dövizi alan ülkelerin, bu döviz kaynağını doğru bir şekilde yönetmek için politikalar geliştirmeleri önemlidir.

Anahtar Kelimeler: Uluslararası göç, işçi dövizleri, yoksulluk, gelişmekte olan ülkeler, havuzlanmış EKK. JEL Kodları: F22, F24, P46

\footnotetext{
*Bu çalışma 07-08 Aralık 2019 tarihlerinde düzenlenen 1. Uluslararası İktisadi İdari Bilimler ve Yerel Yönetimler Kongresinde sunulan "Yoksulluğun Azaltılmasında İşçi Dövizlerinin Rolü: Gelişmekte Olan Ülkeler Üzerine Ampirik Bir Analiz" başlıklı bildirinin genişletilmiş ve yeniden düzenlenmiş halidir.
} 


\section{GiRiş}

Küreselleşen dünyada yeni iş fırsatları, doğum oranlarındaki azalmadan kaynaklanan işgücü kıtlığı, iç çatışmalar ve savaşlar, doğal hastalıklar, iklim değişikliği ve teknolojik gelişmeler yoluyla bilgiye ulaşmanın kolaylaşması gibi faktörler, özellikle uluslararası göç hareketlerini ve göçmen sayısını artırmaktadır. Başka ülkelere göç eden insanların birçoğu, yaşam şartlarını iyileştirmek ve ülkelerine para gönderebilmek umudu taşıyan ekonomik mültecilerdir. Çalışmak amacıyla ülkesinden göç edenlerin ailelerine gönderdikleri para olarak tanımlanan göçmen gönderileri özellikle gelişmekte olan ülkeler için önemli bir sermaye kaynağıdır. Dünya Bankası verilerine göre, düşük ve orta gelirli ülkelere giden göçmen gönderileri 2019 yılında rekor bir seviyeye ulaşmıştır. 2019 yılında dünya genelinde 707 milyar dolarlık göçmen gönderilerinin 551 milyar doları, düşük ve orta gelirli ülkelere giriş yapmıştır. Düşük ve orta gelirli ülkelere giden gönderi miktarı 2018'de bir önceki yıla göre \%8,6 oranında artarken 2019 'da artış hızı yavaşlamış ve \%4,7 oranında artış kaydedilmiştir. Göçmen gönderilerinin artış hızındaki yavaşlamaya sebep olan faktörlerin kaynak ülkenin ekonomik büyüme performansında bozulma, petrol fiyatlarında düşüş, artan jeopolitik riskler, ticaret kısıtlamalarının artması ve döviz kurlarında dalgalanma olduğu ifade edilmektedir (Knomad, 2019). Örneğin $A B D^{\prime}$ de istihdam oranlarının düşmesi Latin Amerika ve Karayipler'e giden gönderi miktarını azaltırken, petrol fiyatlarının düşmesi Rusya'dan Orta Asya ve Doğu Avrupa ülkelerine yönelen işçi dövizini olumsuz etkilemektedir.

Bölgesel olarak değerlendirildiğinde Doğu Asya ve Pasifikte göçmen gönderileri bir önceki yıla oranla \%3,8 oranında artarak 149 milyar dolara, Güney Asya'da \%5,3 düzeyinde yükselerek 139 milyar dolara, Avrupa ve Orta Asya'da ise \%1,8 oranında artışla 59 milyar dolara ulaşmıştır. Çin hariç, düşük ve orta gelirli ülkelere 2018 yılında yapılan göçmen havaleleri 462 milyar dolar iken bu ülkelere yapılan doğrudan yabancı yatırımlar 344 milyar dolar seviyesinde kalmıştır. Düşük ve orta gelir grubundaki bu ülkelerde göçmen gönderileri doğrudan yabancı yatırımlardan daha büyük ve daha istikrarlı bir fon kaynağı olarak görülmektedir. Çünkü yapısı gereği alturistik faktörlerden etkilenen göçmen gönderileri küresel ekonomik ve finansal dalgalanmalardan etkilenmemektedir. 2019 yılında en çok göçmen havalesi alan ülkeler, Hindistan (82 milyar \$), Çin (70 milyar \$), Meksika (38 milyar \$), Filipinler (35 milyar \$) ve Mısır (26 milyar \$)'dır.

2019 yılında göçmen havaleleri, dünya genelinde en büyük döviz kaynağı olmuştur. Bu gelişme, gönderilerin son dönemde ekonomik kalkınmanın bir aracı olarak görülme nedenini de açıklamaktadır. Göçmen gönderilerinin ekonomi üzerindeki etkilerini inceleyen literatür genellikle göçmen gönderilerinin ekonomik büyüme, dış ticaret dengesi, gelir dağıımı üzerindeki etkisine odaklanmaktadır. İlgili literatür incelendiğinde, gönderilerin ekonomi üzerindeki etkileri konusunda kesin bir fikir birliği olmamakla beraber genel olarak gönderilerin olumlu etkilerinin daha fazla olduğu yönündedir. Ahlburg (1996), Taylor ve Wyatt (1996), Rosser (2008) gönderilerin gelir dağıımı eşitsizliğini azalttığını savunurken Giuliano ve Ruiz-Arranz (2005), Adams ve Page (2003), Acosta vd. (2007), Nsiah ve Fayiss (2013) özellikle gelişmekte olan ülkelerde göçmen havalelerinin ekonomiyi canlandırarak ekonomik büyümeyi hızlandırdığını ifade etmektedirler. Ancak literatür son yıllarda özellikle düşük ve orta gelirli ülkelerde gönderilerin yoksulluk üzerindeki etkilerine yoğunlaşmaktadır. Yoksulluk oranı uluslararası fiyatlarla günlük 1.90 doların altında yaşayan nüfus oranı olarak kabul edilmektedir. Dünya Bankası verilerine göre 2020 yılında dünya nüfusunun yaklaşık \%9'unun bu sınırın altında kalacağı tahmin edilmektedir. Yoksul nüfusu, yoksulluğu ölçmede en çok kullanılan gösterge olmakla birlikte yoksulluk derinliği ve yoksulluk şiddeti de yoksulluğu ölçmek için kullanılan diğer göstergelerdir.

Konuyla ilgili literatür işçi gönderilerindeki artışın sadece tüketim harcamalarını değil aynı zamanda tasarrufları ve dolayısıyla yatırımları da etkilediğini vurgulamaktadır (Brown ve Wolker, 1995; Brown ve Leeves, 2007; Ang vd., 2009). Göçmen havaleleri öncelikle hane halkının harcanabilir gelir düzeyinde iyileşme sağladığı için hane halkı tüketimini artıracaktır. Tüketim artışı çarpan etkisi yoluyla üretimi teşvik edecek ve böylece yatırım ve istihdamı pozitif etkileyerek toplumun kalan kısmına fayda sağlayacaktır. Diğer yandan, alıcı hane halkı havalelerin önemli bir kısmını yatırım yapabilmek (özellikle gayrimenkul yatırımı) için tasarruf etmektedir. Ayrıca bu havaleler hane halkı için güvenli ve istikrarlı bir gelir olduğundan onları ticari girişimlerde bulunmaya, yatırım yapmaya ve girişimci risklerini alarak daha fazla gelir elde etmeye teşvik etmektedir. Göçmen havaleleri, alıcılara girişimcilik faaliyetlerinde bulunabilmeleri için işletme sermayesi sağlayarak kredi kısıtlamalarının etkilerini ortadan kaldırmaktadır. Bu sayede küçük ölçekli işletmelerin oluşumu desteklenmekte toplumsal kalkınmaya pozitif katkı sağlamaktadır (Woodruff ve Zenteno, 2001). Diğer taraftan göçmen havaleleri hane halkı gelirini yükselteceği için eğitim ve sağlık harcamaları için daha fazla kaynak ayrılmasına fırsat vermektedir. Bu sayede uzun dönemde yoksulluğu azaltmanın yanı sıra yaşam şartlarını iyileştirerek daha yüksek beşeri sermaye oluşumuna katkı sağlamaktadır. Göçmen dernekleri, yeni sosyal merkezlerin ve hizmetlerin oluşturulmasına, okullar, sağlık merkezleri, yollar ve diğer sosyal projeler yoluyla toplumun tüm kesimlerini olumlu yönde etkilemektedir (Ghosh, 2006; Sorensen ve Pedersen, 2002).

Genel olarak değerlendirildiğinde, göçmen havaleleri hane halkı gelirlerini artırarak hem dayanıklı hem de dayanıklı olmayan malların tüketimini veya tasarrufları desteklemektedir. Hane halkı harcamasının artması çarpan etkisi oluşturarak üretimi ve istihdam olanaklarını yükseltir. Küçük işletmeler için işletme sermayesi sağlar, emek arzını etkiler ve yoksulluğu azaltır. Dahası eğitim, sağlık ve daha iyi beslenme imkanı sağlayarak insan sermayesine artı değer sağlar. Ancak hane halkının bu gelirden 
elde edecekleri fayda onları nasıl ve nerede kullandıklarına bağı̆ olacaktır. Çünkü Bridi (2005)'nin belirttiği üzere bu havaleler alıııların gelir düzeylerini artırdıkları için onları çalışmamaya ve tembelliğe yönlendirebilir. Chami vd. (2005) göçmen gelirlerinin hane halkı üyeleri arasında çalışmaya engel teşkil edecek uyarıcıları tetikleyerek ahlaki bir tehlike sorunu yaratabileceğini belirtmektedir.

Bu çalışmanın amacı, 2019 yılında en fazla göçmen gönderisi alan 10 gelişmekte olan ülkede, göçmen gönderilerinin yoksulluk üzerindeki etkisini incelemektir. Giriş bölümünün ardından ikinci bölümde konuyla ilgili teorik ve ampirik literatür incelemesi yapılmaktadır. Üçüncü bölümde veri seti ve ekonometrik modele yer verilirken dördüncü bölümde metodoloji açıklanmıştır. Ampirik bulguların değerlendirildiği beşinci bölümün ardından sonuç bölümü ile çalışma tamamlanmaktadır.

\section{LITERATÜR TARAMASI}

Göçmen gönderilerinin özellikle düşük ve orta gelirli ülkelerde yoksulluğu azaltmada etkili olup olmadığına dair teorik ve ampirik literatürde fikir birliği yoktur. Göçmen gönderileri ile yoksulluk arasındaki ilişkiyi inceleyen çalışmaların bulguları analize dahil edilen ülke, dönem ve kullanılan yönteme göre farklılık göstermektedir.

Adams (1991), Mısır'ın kırsal bölgelerinde göçmen gönderilerinin yoksul hanelerin sayısını yaklaşık \%9.8 oranında azalttığını ve bu gönderilerin hane halkı gelirlerinin yaklaşı \%14.7'sini oluşturduğunu söylemektedir. Adams ve Page (2003), gelişmekte olan 71 ülke için göçmen gönderileri ve yoksulluk ilişkisini inceledikleri çalışmalarında gelişmekte olan ülkelerde, göçmen gönderilerinin yoksulluk düzeyini, derinliğini ve şiddetini önemli ölçüde azaltabileceğine dair kanıtlar sunmaktadır. Andersen vd. (2005) Nikaragua'da göçmen transferlerinin sosyal hareketlilik ve yoksulluk üzerindeki etkisini incelediği çalışmalarında, gönderilerin bir kişinin birincil gelir kaynağı olmadıkça yoksulluktan veya aşırı yoksulluktan kurtulmasına katkı sağladığına yönelik sonuçlar elde etmişlerdir. Ancak çalışmada, bu durumun emek arzını olumsuz etkilediğine de vurgu yapılmaktadır.

Taylor vd. (2005), Meksika'da göçmen havaleleri, yoksulluk ve gelir eşitsizliği ilişkisini incelemek için 14 Meksika eyaletinde yaklaşık 1.782 haneden veri toplamışlardır. Elde edilen sonuçlara göre, uluslararası göçmen gelirleri yoksulluğu azaltmanın yanı sıra gelir eşitsizliğini de düşürmektedir. Imai vd. (2014), 24 Asya ve Pasifik ülkesi için göçmen gönderilerinin ekonomik büyüme ve yoksulluk üzerindeki etkilerini inceledikleri çalışmalarında, göçmen havalelerinin hem ekonomik büyüme hem de yoksulluğun azaltılmasında pozitif etkileri olduğunu vurgulamaktadırlar. Dünya Bankası'nın (2006) Uluslararası Göç ve Kalkınma Araştırmaları Programı, uluslararası gelirlerin yoksulluk düzeyini ve derinliğini azalttı̆̆ını göstermektedir. Örneğin, göçmen havalelerinde \%10'luk bir artış, kötü koşullarda yaşayan insanların oranında \%3,5'lik bir azalmaya yol açacaktır. Ayrıca bu araştırma programı, göçmen havalelerinin yoksulluk üzerindeki en büyük etkisinin emek alan ülkelere yakın olan ülkelerde gözlendiğini göstermektedir. Yoshino vd. (2017), gelişmekte olan 10 Asya ülkesinde göçmen havalelerinin yoksulluğu azaltmadaki etkisini inceledikleri çalışmalarında, üç yoksulluk göstergesi kullanmışlardır. Çalışmadan elde edilen bulgulara göre, yoksulluk açığı ve yoksulluk şiddeti oranının azaltılmasında göçmen havaleleri istatistiksel olarak anlamlı ve önemli bir etkiye sahiptir. Göçmen havalelerinde oluşacak \%1'lik bir artış, yoksulluk açığını \%22,6 oranında, yoksulluk şiddetini ise \%16 oranında azaltmaktadır. Anyanwu ve Erhijakpor (2010), Afrika ülkelerinde göçmen havalelerinin yoksulluk üzerindeki etkilerini inceledikleri çalışmalarında, 33 Afrika ülkesine ait 1990-2005 dönemi verilerini kullanmışlardır. Çalışmadan elde edilen sonuçlara göre, göçmen gönderileri yoksulluk seviyesini ve yoksulluk derinliğini azaltmaktadır. Ayrıca bu ülkelerde resmi gönderilerin $\% 10$ oranında artması yoksulluğu $\% 2.9$ oranında azaltmaktadır.

Diğer yandan Hein (2005) göçmen gelirlerinin alıcı ülkelerde yaşam koşullarında bir iyileşmeye katkıda bulunmadığını savunmaktadır. Chami, Fullenkamp ve Jahjah (2005), 113 ekonomi için 1970-1998 dönemi verilerini kullanarak işçi gelirlerinin ekonomik büyüme ilişkisini incelediği çalışmasında, göçmen havaleleri ile ekonomik büyüme arasında negatif bir korelasyon olduğu yönünde kanıtlar elde etmişlerdir. Azam ve Gubert (2006), Afrika'daki göçmen gelirlerinin etkilerine değindiği çalışmalarında, bu havalelerin aileler için gelir kaynaklarını çeşitlendirmenin ve tüketimi desteklemenin bir yolu olduğunu ve göçmen havaleleri elde eden hane halkının kendi ülkelerinde daha düşük ücretle çalışmaya razı olduklarını veya çalışmak için daha az çaba gösterdiklerini söylemektedirler. Bu negatif etkiler hem ekonomik büyüme hem de yoksulluk üzerinde negatif etki oluşturmaktadır. Barham ve Boucher (1998), Nikaragua'nın Karayip kıyılarında bulunan Bluefields bölgesi için göçmen gönderileri ve gelir eşitsizliği arasındaki ilişkiyi inceledikleri çalışmalarında, gönderilerin gelir eşitsizliğini daha da artırdığı sonucuna ulaşmışlardır. Lipton (1980) ise Hindistan'ın iç kesimlerindeki 40 köy için yaptığı çalışmada göçün kırsal kesimde gelir eşitsizliğini artırdığını belirtmektedir.

\section{VERI SETI VE EKONOMETRIK MODEL}

Bu çalışma, Dünya Bankası verilerine göre 2019 yılında en fazla göçmen gönderisi alan 10 gelişmekte olan ülkede göçmen gönderilerinin yoksulluk üzerindeki etkisini araştırmaktadır. Yoksulluğun boyutunu ölçmek amacıyla Foster, Greer ve Thorbecke (1984) tarafından metodolojisi geliştirilen üç farklı ölçüt kullanılmıştır. Bu ölçütler yoksul kişi oranı endeksi (lheadcount), yoksulluk açığı endeksi (lpovgap) ve yoksulluk oranının karesi-yoksulluk şiddeti endeksidir (sqlpovgap). Analiz için 1996-2016 dönemine ait 81 adet gözlem değeri bulunmaktadır. Değişkenlere ait verilerin kesikli olması ve gözlem 
sayısının düşüklüğü nedeniyle statik panel yöntemlerinden havuzlanmış EKK, sabit etkiler ve rassal etkiler modeli ile tahmin yapılmıştır. Panel Bangladeş, Çin, Hindistan, Filipinler, Meksika, Mısır, Nijerya, Ukrayna, Pakistan ve Vietnam'dan oluşmaktadır. Tüm değişkenlerin doğal logaritmaları alınmış ve ekonometrik analiz için Eviews 10 paket programı kullanılmıştır.

En yaygın yoksulluk ölçütü olarak kullanılan yoksul kişi oranı endeksi, yoksul olarak kabul edilen kişi sayısının toplam nüfusa oranlanması ile ölçülmektedir. Hesaplama kolaylığı sunmasının ve anlaşılabilirliğinin aksine bu ölçüt, yoksulluğun derinliği hakkında bilgi vermemektedir. Bu çalışmada yoksul kişi oranı endeksi için günlük $1.90 \$$ sınırın altında gelir elde eden nüfusun toplam nüfusa oranı kullanılmıştır. Yoksul kişi oranı endeksine göre yoksulluğu daha derinlemesine inceleyen ve gelir açığı kavramına dayanan ikinci ölçüt ise yoksulluk açığı endeksidir. Bu endekste yoksulluk sınırı ile bireyin geliri arasındaki fark alınarak ölçüm yapılmaktadır. Üçüncü ölçüt ise yoksullar arasındaki eşitsizliği dikkate almak amacıyla geliştirilen yoksulluk açığının karesi-yoksulluk şiddeti endeksidir (Adams ve Page, 2005: 1647).

Adams ve Page (2005), Anyanwu ve Erhijakpor (2010), Imai vd. (2014), Abduvaliev ve Bustillo (2019) çalışmalarından hareketle göçmen gönderilerinin yoksulluk üzerine etkisini tespit etmek amacıyla tahmin edilecek uzun dönem denklemi Eşitlik 1'de yer almaktadır.

lpoverty $_{i t}=\beta_{0}+\beta_{1}$ lgini $_{i t}+\beta_{2}$ lrem $_{i t}+\beta_{3}$ linf $_{i t}+\beta_{4}$ lopen $_{i t}+\beta_{5} \operatorname{lgdppc}_{i t}+\mu_{i}+\varepsilon_{i t}$

Eşitlik 1 'de $i$ yatay kesit birimlerini, $t$ zaman boyutunu, $\varepsilon_{i t}$ hata terimi, $\mu_{i}$ ise kesite özgü gözlenemeyen etkileri göstermektedir. Modelin bağımsız değişkenlerinden lgini gelir eşitsizliğini ölçen Gini katsayısını, lrem toplam göçmen gönderisi girişlerini, linf tüketici fiyat endeksi ile ölçülen enflasyon oranını, lopen ülkenin dış dünyaya açıklık düzeyini, $\lg d p p c$ ise kişi başı GSYH'yı göstermektedir. Ampirik analizde kullanılan değişkenlere ait kısaltmalar ve açıklamalar Tablo 1'de özetlenmiştir.

Tablo 1: Değişkenlere Ait Kısaltma ve Açıklamalar

\begin{tabular}{|c|c|c|}
\hline Değişken & Değişkenin Açıklaması & Veri Kaynağı \\
\hline lheadcount & $1.90 \$$ altında geliri olanların toplam nüfusa oranı & \\
\hline lpovgap & Yoksulluk açı̆̆ı endeksi & \\
\hline lsqpovgap & Yoksulluk açığının karesi-yoksulluk şiddeti endeksi & World Bank, PovcalNet Database \\
\hline lgini & Gini katsayı & \\
\hline lrem & Göçmen gönderisi girişlerinin GSYH'ya oranı & \\
\hline $\operatorname{linf}$ & Tüketici fiyat endeksi $(2010=100)$ & World Bank, World Development \\
\hline lopen & İthalat ve ihracat toplamının GSYH içindeki payı & Indicator \\
\hline $\lg d p p c$ & Kişi başı GSYH (2010 yılı sabit fiyatlarıyla) & \\
\hline
\end{tabular}

Yüksek gelir eşitsizliği, yüksek düzeyde yoksulluk ile ilişkilendirilebileceği için gelir eşitsizliğini temsil eden lgini değişkenine ait $\beta_{1}$ katsayısının pozitif işarete sahip olması beklenmektedir. Göçmen gönderilerinin yoksulluk üzerine etkisini ölçmek üzere tahmin edilecek $\beta_{2}$ katsayısının literatürde pozitif veya negatif işaret aldığı çalışmalar bulunmaktadır. Göçmen gönderisi alan ülkelerde yoksulluğun düşük seviyelere ineceği, artan gelir düzeyi neticesinde fiziksel ve beşeri sermaye yatırımlarının artacağı beklenmektedir. Artan gelirin tüketim eğilimini yükseltmesi sonucunda da yoksulluk üzerinde azaltıcı etki yaratacağı tahmin edilmektedir. Ancak nitelikli işgücünün göçmen gönderisine güvenerek çalışma hayatından vazgeçmesi durumunda uzun dönem büyüme oranları ve yoksulluk üzerinde olumsuz etkilerin ortaya çıkması muhtemeldir. Ayrıca göçmen gönderisi alan ve gönderen taraflar arasında uzun dönemde ortaya çıkan birbirine bağımlılık da göçmen gönderilerinin yoksulluk üzerinde yaratacağı etkiye dair kesin bir kanıya ulaşmaya engel olmaktadır.

Yurtiçi fiyat düzeyindeki yükselişi ve hayat pahalılı̆ı ölçmek amacıyla regresyon denkleminde yer alan linf değişkeninde ortaya çıkacak bir artış, geleceğe dair belirsizlik yaratan bir risk unsuru olacaktır. Bu doğrultuda enflasyon oranlarında yükselme büyüme potansiyeli üzerinde negatif etki yaratacak ve yoksulluğun şiddetini artıracaktır. Bu nedenle $\beta_{3}$ katsayısının pozitif işaret alması beklenmektedir. Ülkenin dış dünya ile ticari entegrasyon düzeyindeki artış, özel sektörün faaliyet hacmini artırmasının yanısıra yabancı yatırımları teşvik ederek ülkede yoksulluğun azalmasına yardımcı olmaktadır. Bu doğrultuda $\beta_{4}$ katsayısının negatif işaret alması beklenmektedir. Kişi başı reel GSYiH'nın doğal logaritmasını temsil eden lgdppc değişkeninde ortaya çıkması muhtemel artışlar yoksulluğu azaltacağı için $\beta_{5}$ katsayısının da negatif işarete sahip olacağı tahmin edilmektedir.

\section{METODOLOJI VE AMPIRIK BULGULAR}

Ekonometrik analizlerde kullanılan veri türleri, zaman serisi, yatay kesit ve panel veriden oluşmaktadır. Değişkenlerin belirli bir zaman diliminde seyrini gösteren veriler zaman serisi olarak adlandırılırken zamanın belirli bir kesitinde farklı birimlere 
ilişkin değerlerden oluşan seriler ise yatay kesit olarak tanımlanmaktadır (Vijayamohanan, 2016: 3). Panel veri setleri ise hanehalkı, ülke, firmalar gibi yatay kesit birimlerine ait gözlemlerin bir zaman periyodundaki seyrini göstermektedir. Bu doğrultuda panel veri setleri, yatay kesit $(N)$ ve zaman $(T)$ olmak üzere iki farklı boyuta sahiptir (Hsiao, 2003: 1, 7).

Panel veri regresyonu Eşitlik 2'de gösterilmektedir.

$y_{i t}=x_{i t}^{\prime} \beta+\alpha_{i}+\varepsilon_{i t} \quad t=1,2, \ldots, T \quad i=1,2, \ldots N$

Yukarıdaki regresyon modelinde $\alpha_{i}$, incelenen zaman dilimi boyunca değişim göstermeyen ve sabit kalan bir dizi gözlenebilen grup spesifik değişkenleri (ırk, cinsiyet, konum gibi) veya gözlenemeyen spesifik etkileri (aileye özgü özellikler, bireysel yetenek veya tercihler gibi) içermektedir. $\alpha_{i}$, zaman içinde değişmeden sabit kaldığı için zaman boyutunu temsil eden $t$ terimini içermemektedir. Bu yöntemde grup spesifik etkiler sabit terimin bir parçası olarak düşünülmekte ve hata teriminin diğer açıklayıcı değişkenlerle ilişkili olduğu kabul edilmektedir. Gözlenemeyen etkileri içeren ve incelenen zaman diliminde sabit kalan bu tür modeller, sabit etkiler modeli olarak isimlendirilir (Wooldridge, 2012: 456).

Sabit etkiler modeli, yatay kesit birimleri arasındaki farklılığın sabit olduğunu ve farklılıkların sabit terimle ifade edileceğini varsaymaktadır. Ancak yatay kesit birimleri arasındaki farklılıklar tesadüfü olarak ortaya çıkabilmektedir. Rassal etkiler modelinde bireysel farklılık tesadüfi olarak belirlendiği için hata terimi içinde yer alacaktır. Bu doğrultuda $u_{i}$ grup spesifik rassal bileşen olmak üzere panel veri regresyonunu aşağıdaki gibi yazılabilecektir (Greene, 2003: 285).

$$
y_{i t}=x_{i t}^{\prime} \beta+\alpha+u_{i}+\varepsilon_{i t}
$$

Sabit etkiler modeli, LSDV (least squares dummy variable) grup içi tahmin yöntemini kullanmasına rağmen rassal etkiler modeli GLS (generalized least squares) ile tahmin edilmektedir. Rassal etki modellerinin sabit etkiler modelinden gösterildiği bir diğer farklılık ise hata teriminin hiçbir açıklayıcı değişken ile korelasyonlu olmamasına yöneliktir. Rassal etki modelinde yatay kesit birimlerine özgü gözlenemeyen özelliklerin tesadüfi olarak dağıldığı varsayılmaktadır. Dolayısıyla hata terimi ile yakalanan bu özelliklerin bir kısmı zaman içinde sabit kalırken diğer kısmı zamanla değişim göstermektedir. Eşitlik 3'te $u_{i}$ tesadüfi dağılan hata terimlerinin zaman içinde sabit kalan kısmını ifade etmektedir (Greene, 2003: 285).

Birim ve zaman boyutu etkisini içeren bir panel regresyonunda havuzlanmış EKK, sabit etki ve rassal etki tahmincileri arasında seçim yapmaya yardımcı olacak bazı testler kullanılmaktadır. Havuzlanmış EKK ve sabit etki modelleri arasında LM testi yardımıyla seçim yapılırken, sabit ve rassal etki tahmincileri arasındaki tercih için Hausman (1978) spesifikasyon testi uygulanmaktadır. $\mathrm{F}$ testi sonucunda boş hipotezin reddedilmesi sabit etkiler modelinin havuzlanmış EKK tahmincisine göre daha etkin olacağı anlamına gelecektir (Vijayamohanan, 2016: 4). Hausman testi ise boş hipotezde rassal etkiler tahmincisinin, alternatif hipotezde ise sabit etkiler tahmincisinin daha geçerli olduğunu test etmektedir (Yerdelen Tatoğlu, 2013: 179-180).

Çalışmada kullanılan tüm değişkenlere ait tanımlayıcı istatistikler Tablo 2'de raporlanmıştır. Analizde yer alan değişkenler içinde en düşük sapma değerini Gini katsayısı alırken en yüksek sapma değeri yoksulluk şiddeti endeksine aittir. Çalışmanın bağımlı değişkenlerinden yoksul kişi oranı endeksi 1.5, yoksulluk açığı endeksi 0.07 ve yoksulluk şiddeti endeksi ise 0.5 ortalama değerine sahiptir. Çarpıklık (skewness) katsayısı yoksulluk endeksleri, göçmen gönderisi ve enflasyon oranı değişkenlerinin sola çarpık; Gini katsayısı, dışa açıklık oranı ve kişibaşı GSYH'nın ise sağa çarpık bir dağılım gösterdiğine işaret etmiştir. Basıklık (kurtosis) değerlerine göre Gini katsayısı, dışa açıkık oranı ve kişi başı GSYH'nın kalın kuyruklu, diğer değişkenlerin ise ince kuyruklu olduğu gözlenmiştir. Basıklık ve çarpıklık istatistiklerinin yanı sıra Jarque-Bera olasılık değeri de serilerin normal dağılıma uygun olmadığını teyit etmektedir.

Tablo 2: Tanımlayıcı İstatistikler

\begin{tabular}{lcccccccc}
\hline & lheadcount & lpovgap & sqlpovgap & lgini & lrem & linf & lopen & lgdppc \\
\hline Ortalama & 1.567 & 0.071 & 0.518 & 3.603 & 0.757 & 4.283 & 4.087 & 7.792 \\
Medyan & 1.897 & 0.470 & 1.965 & 3.565 & 1.061 & 4.384 & 3.959 & 7.631 \\
Maksimum & 4.151 & 3.436 & 13.74 & 3.977 & 2.540 & 5.054 & 5.218 & 9.230 \\
Minimum & -4.605 & -4.605 & -18.42 & 3.231 & -4.307 & 2.849 & 3.319 & 6.263 \\
Std. sapma & 1.652 & 1.729 & 6.634 & 0.202 & 1.405 & 0.460 & 0.494 & 0.843 \\
Çarpıklık & -1.206 & -0.888 & -0.842 & 0.310 & -1.383 & -0.627 & 0.495 & 0.386 \\
Basıklık & 4.674 & 3.776 & 3.832 & 1.840 & 4.607 & 3.178 & 2.189 & 1.973 \\
Jarque-Bera & 29.11 & 12.68 & 11.77 & 5.840 & 34.55 & 5.429 & 5.526 & 5.578 \\
Olasılık & 0.00 & 0.001 & 0.00 & 0.053 & 0.000 & 0.066 & 0.063 & 0.061 \\
Gözlem & 81 & 81 & 81 & 81 & 81 & 81 & 81 & 81 \\
\hline
\end{tabular}


Uzun dönem regresyon modelinde yer alan değişkenler arası korelasyon matrisi Tablo 3'te raporlanmıştır. Tabloda yer alan değerler incelendiğinde üç yoksulluk göstergesi arasında çok güçlü bir pozitif korelasyon olduğu dikkat çekmektedir. Ayrıca yoksulluk göstergelerinin gelir eşitsizliğini ölçen Gini katsayısı ve göçmen gönderileri ile pozitif; enflasyon oranı, dışa açıklık oranı ve kişi başı GSYH ile negatif korelasyonlu olduğu görülmektedir. Göçmen gönderilerine ait bulgular, bu değişkenin yoksul kişi oranı endeksi ile \%14, yoksulluk açığı endeksi ile \%7 ve yoksulluk şiddeti endeksi ile \%9 oranında pozitif korelasyonlu olduğunu göstermiştir. Ayrıca göçmen gönderilerinin enflasyon oranı ve dışa açıklık oranı ile pozitif, kişibaşı GSYH ile negatif korelasyonlu olduğu bilgisi elde edilmiştir. Bunun yanı sıra kişi başı GSYH ile yoksul kişi oranı endeksi arasındaki negatif korelasyon \%37 oranında iken yoksulluk açığı ve yoksulluk şiddeti endeksleri arasındaki korelasyon \%25 olarak bulunmuştur.

Tablo 3: Korelasyon Matrisi

\begin{tabular}{|c|c|c|c|c|c|c|c|c|}
\hline & lheadcount & lpovgap & sqlpovgap & lgini & lrem & $\operatorname{linf}$ & lopen & lgdppc \\
\hline lheadcount & 1.00 & & & & & & & \\
\hline lpovgap & 0.97 & 1 & & & & & & \\
\hline sqlpovgap & 0.98 & 0.99 & 1 & & & & & \\
\hline $\operatorname{lgini}$ & 0.41 & 0.52 & 0.50 & 1 & & & & \\
\hline lrem & 0.14 & 0.07 & 0.09 & 0.03 & 1 & & & \\
\hline $\operatorname{linf}$ & -0.25 & -0.26 & -0.27 & 0.04 & 0.28 & 1 & & \\
\hline lopen & -0.26 & -0.24 & -0.22 & 0.01 & 0.16 & -0.08 & 1 & \\
\hline $\operatorname{lgdppc}$ & -0.37 & -0.25 & -0.25 & 0.54 & -0.28 & 0.16 & 0.06 & 1 \\
\hline
\end{tabular}

Korelasyon analizi, iki değişken arasındaki karşılıklı ilişkiyi göstermek açısından önemli bilgiler sunmasına rağmen uzun dönemde değişkenler arası ilişkinin yönünün tespiti için bağımlı değişkeni etkileyebilecek diğer tüm açıklayıcı değişkenler ile regresyon analizi yapılması daha sağlıklı sonuçlar verecektir.

Tablo 4, Eşitlik 1'de ifade edilen uzun dönem denklemine ait havuzlanmış EKK, sabit etki ve rassal etki modellerine ait tahmin sonuçlarını göstermektedir. Tahmin yöntemlerine ait sonuçlar arasında en uygun olanın belirlenmesi için bazı testlerin uygulanması gerekmektedir. Bu nedenle havuzlanmış EKK ve sabit etki modellerinden hangisinin daha tutarlı sonuçlar vereceğini belirlemek için $\mathrm{F}$ testi, EKK ve rassal etkiler modeli arasında tercih yapmak için LM testi ve son olarak sabit etkiler ve rassal etkiler modelleri arasında seçim için Hausman testi uygulanmıştır. Tablo 4 'te yer alan $\mathrm{F}$ testi bulguları tüm regresyonlarda sabit etkiler modelinin EKK'dan daha tutarlı bir tahmin olduğunu göstermiştir. Benzer şekilde LM test istatistiği de rassal etkiler modelinin EKK'dan daha üstün olduğuna işaret etmiştir. Üç farklı yoksulluk ölçütünün sırasıyla bağımlı değişken olduğu uzun dönem denkleminin tahmininde kullanılacak en uygun yöntemin belirlenmesi için son olarak Hausman (1978) tarafından geliştirilen test istatistiği kullanılmıştır. Üç modele ilişkin Hausman test sonuçlarına göre \%99 önem düzeyinde sabit etkiler modelinin daha tutarlı ve etkin sonuçlar verdiği belirlenmiştir.

Tablo 4: Uzun Dönem Katsayı Tahmin Sonuçları

\begin{tabular}{|c|c|c|c|c|c|c|c|c|c|}
\hline \multirow{2}{*}{$\begin{array}{l}\text { Bağımlı } \\
\text { değişken }\end{array}$} & \multicolumn{3}{|c|}{ Yoksul kişi oranı } & \multicolumn{3}{|c|}{ Yoksulluk açığı } & \multicolumn{3}{|c|}{ Yoksulluk şiddeti } \\
\hline & OLS & $\mathrm{FE}$ & $\mathrm{RE}$ & OLS & $\mathrm{FE}$ & $\mathrm{RE}$ & OLS & $\mathrm{FE}$ & RE \\
\hline \multirow{2}{*}{$\operatorname{lgini}$} & 7.148 & 1.632 & 5.187 & 8.171 & 0.880 & 4.872 & 20.27 & 2.158 & 20.27 \\
\hline & $(0.00)$ & $(0.30)$ & $(0.00)$ & $(0.00)$ & $(0.61)$ & $(0.00)$ & $(0.05)$ & $(0.72)$ & $(0.00)$ \\
\hline \multirow{2}{*}{ lrem } & -0.034 & -0.226 & -0.177 & -0.118 & -0.268 & -0.215 & -0.811 & -1.066 & -0.811 \\
\hline & $(0.65)$ & $(0.05)$ & $(0.05)$ & $(0.13)$ & $(0.01)$ & $(0.13)$ & $(0.50)$ & $(0.01)$ & $(0.05)$ \\
\hline \multirow{2}{*}{$\operatorname{linf}$} & 0.610 & 0.479 & 0.516 & 0.661 & 0.822 & 0.705 & 2.774 & 2.313 & 2.774 \\
\hline & $(0.00)$ & $(0.11)$ & $(0.03)$ & $(0.00)$ & $(0.00)$ & $(0.00)$ & $(0.01)$ & $(0.00)$ & $(0.01)$ \\
\hline \multirow{2}{*}{ lopen } & -0.768 & 0.273 & -0.295 & -0.713 & 0.256 & -0.162 & -0.913 & 0.852 & -0.913 \\
\hline & $(0.00)$ & $(0.54)$ & $(0.31)$ & $(0.00)$ & $(0.54)$ & $(0.62)$ & $(0.50)$ & $(0.61)$ & $(0.50)$ \\
\hline \multirow{2}{*}{$\operatorname{lgdppc}$} & -1.598 & -2.564 & -2.021 & -1.567 & -2.121 & -1.938 & -7.474 & -8.187 & -7.474 \\
\hline & $(0.00)$ & $(0.00)$ & $(0.00)$ & $(0.00)$ & $(0.00)$ & $(0.00)$ & $(0.00)$ & $(0.00)$ & $(0.00)$ \\
\hline \multirow{2}{*}{ sabit } & -5.948 & 16.77 & 2.114 & -11.32 & 16.11 & 1.433 & 1.593 & 68.01 & 1.593 \\
\hline & $(0.00)$ & $(0.00)$ & $(0.53)$ & $(0.00)$ & $(0.00)$ & $(0.73)$ & $(0.92)$ & $(0.00)$ & $(0.92)$ \\
\hline$R^{2}$ & 0.77 & 0.89 & 0.68 & 0.78 & 0.91 & 0.70 & 0.77 & 0.90 & 0.68 \\
\hline$\overline{R^{2}}$ & 0.75 & 0.86 & 0.65 & 0.77 & 0.89 & 0.68 & 0.75 & 0.88 & 0.66 \\
\hline \multirow{2}{*}{$F$ test } & 2.76 & & & 9.96 & & & 10.00 & & \\
\hline & $(0.00)$ & & & $(0.00)$ & & & $(0.00)$ & & \\
\hline$L M$ test & & & 6.96 & & & 8.71 & & & 8.03 \\
\hline
\end{tabular}




\begin{tabular}{|c|c|c|c|c|c|c|c|c|c|}
\hline \multirow{3}{*}{$\begin{array}{l}\text { Hausman } \\
\text { test } \\
\text { Gözlem }\end{array}$} & \multicolumn{3}{|c|}{$(0.00)$} & \multicolumn{5}{|c|}{$(0.00)$} & \multirow[t]{2}{*}{$(0.00)$} \\
\hline & & $\begin{array}{l}26.16 \\
(0.00)\end{array}$ & & & $\begin{array}{l}25.8 \\
(0.00\end{array}$ & & & $\begin{array}{l}26.75 \\
(0.00)\end{array}$ & \\
\hline & 81 & 81 & 81 & 81 & 81 & 81 & 81 & 81 & 81 \\
\hline
\end{tabular}

Not: Olasılık değerleri parantez içinde verilmiştir. OLS havuzlanmış EKK, FE sabit etkiler, RE ise rassal etkiler modeli ile tahmin yapıldığııı ifade etmektedir.

Tablo 4'te raporlanan F testi, LM testi ve Hausman test istatistikleri birlikte değerlendiğinde üç yoksulluk göstergesinin bağımlı değişken olarak yer aldığı uzun dönem regresyonları için en uygun tahmincinin sabit etkiler modeli olduğu tespit edilmiştir. Sabit etkiler modeli ile tahmin edilen uzun dönem regresyonlarında otokorelasyon ve değişen varyans sorunlarının varlığı test edilmiş ve bu sorunların ortadan kaldırıması için Beck ve Katz (1995) tarafından geliştirilen PCSE (Panel Corrected Standard Errors) düzeltmesi uygulanmıştır.

Değişen varyans ve otokorelasyon sorunlarından arındırılmış sabit etkiler modeline ait sonuçlar incelendiğinde uzun dönemde göçmen gönderilerinin tüm yoksulluk göstergeleri üzerinde negatif yönlü ve \%95 önem düzeyinde anlamlı etkilere sahip olduğu belirlenmiştir. Bu sonuç en fazla göçmen gönderisi alan 10 gelişmekte olan ülkede 1996-2016 dönemi için göçmen gönderilerinin yoksulluğu azaltıcı etkilere sahip olduğunu göstermektedir. Benzer şekilde kişi başı gelir düzeyindeki artışın yoksulluk üzerine etkisi negatif yönlü ve \%99 düzeyinde anlamlıdır. Gelir eşitsizliği yoksulluk endekslerini pozitif yönde etkilemesine rağmen sonuçlar istatistiksel açıdan anlamlı çıkmamıştır. Yurtiçi fiyat düzeyinin göstergesi olarak modellerde yer alan linf değişkeni her üç modelde pozitif işaret alsa da yoksulluk açığı ve yoksulluk şiddeti endekslerinin bağımlı değişken olduğu modeller istatistiksel açıdan anlamlıdır. Ülkenin dış dünya ile entegrasyon düzeyinin bir ölçütü olarak modellerde yer alan lopen değişkeninin pozitif işaret alacağı tahmin edilmesine rağmen negatif katsayılara ulaşılmıştır. Ancak bu sonuçlar istatistiksel olarak anlamlı değildir.

Tablo 1'de yer alan sabit etkiler modeli tahminlerine ait $R^{2}$ istatistikleri incelendiğinde yoksul kişi oranı ve yoksulluk açığı endeksinin bağımlı değişken olduğu modellerde bağımlı değişkendeki değişmelerin yaklaşık \%90'ının bağımsız değişkenler tarafından açıklandığı görülmektedir. Yoksulluk şiddetinin bağımlı değişken olduğu modeldeki değişmelerin ise \%62'si bağımsız değişkenler tarafından açıklanmaktadır.

\section{SONUÇ VE DEĞERLENDIRME}

Uluslararası Göç Örgütü’nün (IOM) 2020 Dünya Göç Raporu'na göre dünya genelinde 272 milyona ulaşan göçmen sayısı, dünya nüfusunun yaklaşık yüzde 3,5'ine tekabül etmektedir. Dünyada artan bölgesel gerginlikler, savaşlar, siyasi baskılar, doğal afetler, iklim değişiklikleri gibi pek çok faktör göçün nedenleri arasında yer alsa da uluslararası göçün en önemli belirleyicileri ekonomik faktörlerdir. Göçmenlerin birçoğu daha iyi hayat şartlarına sahip olabilmek için ülkelerini terk ederken bazıları da geride bıraktıkları yakınlarının ihtiyaçlarını karşılayabilmek için göç etmektedirler. Gelir düzeyi düşük birçok ülkede göçmenlerin yakınlarına gönderdikleri havaleler oldukça önemli bir seviyeye ulaşmış ve bu ülkeler için önemli bir döviz kaynağı haline gelmiştir. Bu havalelerin dış ticaret açığı, finansal gelişme, gelir dağılımı ve yoksulluk üzerine etkileri son dönemde literatürde sıklıkla incelenen konular arasında yer almaktadır.

Bu çalışma Dünya Bankası verilerine göre 2019 yılında en fazla göçmen gönderisi alan 10 gelişmekte olan ülkede göçmen gönderilerinin yoksulluk üzerinde yarattığı etkiyi tespit etmeyi amaçlamaktadır. Yoksulluk ölçütü olarak literatürde yaygın kabul gören göstergelerden yoksul kişi oranı endeksi, yoksulluk açığı endeksi ve yoksulluk şiddeti endeksinden yararlanılmıştır. 1996-2016 dönemini kapsayan ampirik analiz için statik panel veri analiz yöntemleri kullanılmıştır. Yapılan ön testler sonucunda en uygun tahmincinin sabit etkiler modeli olduğu belirlenmiş ve bu yöntem ile elde edilen uzun dönem katsayılar göçmen gönderilerinin tüm yoksulluk endeksleri üzerinde negatif yönlü ve anlamlı etkilere sahip olduğunu göstermiştir. Ayrıca uzun dönemde kişi başı gelir düzeyinde artış, yoksulluğu azaltıcı etkilere sahipken enflasyon oranlarında yükseliş sonucu hayat pahalıı̆ı̆ının artması, yoksulluğu derinleştirmektedir. Genel olarak değerlendirildiğinde en fazla uluslararası göç veren ülkelerin, işsizlik rakamlarının yüksek ve ekonomisi güçlü ülkelere coğrafi olarak yakın olduğu görülmektedir. Çünkü yüksek gelirli ülkeler, uluslararası göçmenlerin çoğu için hedef ülkelerdir. Tüm dünyadaki göçmen işçi sayısının yaklaşık \%36' sı orta veya düşük gelirli ülkelerde yaşamaktadır. En çok göçmen işçi barındıran ülke 2018 yılında 49,8 milyon işçi ile Amerika Birleşik Devletleri, ikinci sırada Suudi Arabistan sonra Almanya ve sırasıyla Rusya ve İngiltere'dir. Bu çalışmada incelenen ülkelerin çoğunun coğrafi olarak ekonomisi güçlü ve göç alan ülkelere yakın olduğu görülmektedir. Dünya Bankası'nın yayımladığı Uluslararası Göç ve Para Transferleri raporuna göre 2018 yılında Hindistan 78,6 milyar dolar, Çin 67,4, Meksika 35,7, Filipinler 33,8 ve Mısır 28,9 milyar dolar göçmen gönderisi almıştır. Bu rakamlar düşük ve orta gelirli ülke vatandaşları için oldukça önemli bir gelir kaynağı olmakta, gönderiyi alan bireylerin gelir düzeyine ciddi katkı sağlamakta ve yoksulluğu azaltmaktadır. 
Daha iyi yaşam şartlarına ulaşmak amacıyla ülkelerini terk eden göçmenlerin ülkelerine gönderdikleri transferler son yıllarda oldukça önemli boyutlara ulaşmıştır. Bu gönderiler, aile ekonomisine katkı sağlayarak yoksulluğun azaltılması, hane halkııın tasarruf ve yatırımlarının artması yoluyla ekonomik kalkınmayı destekleyen önemli bir döviz kaynağı haline gelmektedir. Diğer yandan iş̧̧i dövizleri sayesinde gelir düzeyi artan ailelerin eğitim ve sağılk alanında yatırım yapmaları ülkenin beşeri sermaye kalitesini de yükseltecektir. Bu nedenle başlangıçta olumsuz bir olgu gibi gözüken uluslararası göçün aslında birçok ülke için pozitif katkıları olmaktadır. Ancak burada önemli olan yüksek işçi dövizi alan ülkelerin bu döviz kaynağını doğru alanlara yönlendirecek politikalar üretmeleri ve bunları hayata geçirebilmeleridir.

\section{KAYNAKLAR}

Abduvaliev, M. ve Bustillo, R. (2019). "Impact of Remittances on Economic Growth and Poverty Reduction amongs CIS Countries", PostCommunist Economies, 32(4), 525-546.

Acosta, P., Fajnzylber, P. ve Lopez, J.H. (2007). "The Impact of Remittances on Poverty and Human Capital: Evidence from Latin American Household Surveys", World Bank Policy Research Working Paper,4247, WPS4247.

Adams, R. (1991). 'The Effects of International Remittances on Poverty, Inequality, and Development in Rural Egypt', IFPRI Research Report 86, Washington.

Adams, R. ve Page, J. (2003). "International Migration Remittances and Poverty in Developing Countries", Policy Research Working Paper, No:3179, Washington, DC.

Adams, R. ve Page, J. (2005). “Do International Migration and Remittances Reduce Poverty in Developing Countries?", World Development, 33(10), 1645-1669.

Ahlburg, D.A, (1996). “Remittances And The Income Distribution in Tonga”, Population Research and Policy Review, 15(4), 391-400.

Andersen, L., Christensen, B. ve Tejerina, O. M. (2005). The Impact of Aid on Recipient Behavior: A Micro-Level Dynamic Analysis Of Remittances, Schooling, Work, Consumption, Investment and Social Mobility in Nicaragua, Grupo Integral Study No. GI-E12.

Ang A. P., Sugiyarto, G. ve Jha, S. (2009). Remittances and Household Behavior in the Philippines. ADB Economics Working Paper Series No. 188. Manila: Asian Development Bank.

Anyanwu, J.C. ve Erhijakpor, A. E.O., (2010). “Do International Remittances Affect Poverty in Africa?”,African Development Review, 22(1) 5191.

Azam, J.-P. ve F. Gubert (2006). 'Migrants' Remittances and the Household in Africa: A Review of Evidence', Journal of African Economies, Vol. 15, AERC Supplement 2, 426-62.

Baltagi, B. H. (2005). Econometric Analysis of Panel Data, Third Edition. NewYork: John Wiley and Sons Publication.

Barham, B. ve Boucher, S. (1998). "Migration, Remittances, and Inequality: Estimating The Net Effects of Migration on Income Distribution", Journal of Development Economics, 55,307-31.

Beck, N. ve Katz, J. N. (1995). "What to Do (and Not to Do) with Time-Series Cross-Section Data," American Political Science Review, 89, 634647.

Bridi, H. (2005). Consequences of Labour Migration for the Developing Countries Management of Remittances, World Bank Brussels Office.

Brown, R. P., ve Walker, C. (1995). Migrants and Their Remittances: Results of a Household Survey of Tongans and Estern Samoans in Sidney, Pacific Studies Monograph, No:17, Centre for South Pacific Studies, University of New South Wales.

Brown, R. P., ve Leeves, G. (2007). Impacts of International Migration and Remittances on Source Country Household Incomes in Small Island States; Fiji and Tonga. Working Papers 07-13. Rome: Agricultural and Development Economics Division, Food and Agriculture Organization.

Chami, R., C. Fullenkamp ve Jahjah, S. (2005). 'Are Immigrant Remittances Flows a Source of Capital for Development?', IMF Staff Papers, 52, (1).

Foster, J., Greer, J. ve Thorbecke, E. (1984). “A Class of Decomposable Poverty Measures,” Econometrica, 52(3): 761-766.

Ghosh, B. (2006). 'Migrants' Remittances and Development: Myths, Rhetoric and Realities', International Organization for Migration (IOM).

Giuliano, Paola ve Ruiz-Arranz, Marta (2005). Remittances, Financial Development, and Growth. IMF Working Paper Research Department, WP/05/234.

Greene, W. H. (2003). Econometric Analysis, Fifth Edition. New Jersey: Prentice Hall.

Hausman, J. A. (1978). "Specification Tests in Econometrics," Econometrica, 43, 727-738.

Hein, D. H. (2005). “International Migration, Remittances and Development: Myths and Facts.” Third World Quarterly 26 (8): $1269-84$. 
Hsiao, C. (2003). Analysis of Panel Data, Second Edition. Cambridge: Cambridge University Press.

Imai, K. S., Gaiha, R., Ali, A. ve Kaicker, N. (2014). "Remittances, Growth, and Poverty: New Evidence from Asian Countries." Journal of Policy Modeling 36: 524-38.

Knomad, Remittances Data (2019). Migration and Remittances: Recent Developments and Outlook. Migration and Development Brief 31, April 2019, World Bank.

Lipton, M. (1980). "Migration from Rural Areas of Poor Countries: The Impact on Rural Productivity and Income Distribution", World Development, 8(1), 1-24.

IOM (2000). World Migration Report, 2020.

Nsiah, C. ve Fayissa, B. (2013). "Remittances And Economic Growth in Africa, Asia and Latin American-Caribbean Countries: A Panel Unit Root and Panel Cointegration Analysis", Journal of Economics and Finance, 37(3), 424-441.

Rosser, E. (2008). “Immigrant Remittances”, Connecticut Law Review, 41(1), 1-61.

Sorensen, N. ve Pedersen, P. (2002). 'The Migration and Development Nexus: Evidence and Policy Options', Policy Study, Center for Development Research (CDR), Copenhagen.

Taylor, J. E.ve Wyatt, T.J. (1996). "The Shadow Value of Migrant Remittances, Income and Inequality in A Household-Farm Economy." Journal of Development Studies, 32(6), 899-912.

Taylor, J.E., Mora, J., Adams, R. ve Lopez-Feldman, A. (2005). 'Remittances, Inequality and Poverty: Evidence from Rural Mexico', Working Paper No. 05-003, Department of Agricultural and Resource Economics, University of California, Davis.

Vijayamohanan, P. N. (2016). Panel Data Analysis with Stata Part 1: Fixed Effects and Random Effects Models. MPRA Paper No. 76869

Woodruff, C. ve Zenteno, R. (2001). Remittances and Microenterprices in Mexico, Graduate School of International Relations and Pacific Studies Working Paper.

Wooldridge, J. M. (2012). Introductory Econometrics: A Modern Approach, Fifth Edition. Ohio: South-Western, Cengage Learning.

Yerdelen Tatoğlu, Ferda (2013). Panel Veri Ekonometrisi: Stata Uygulamalı. Beta Basım Yayın, İstanbul.

Yoshino, N., Taghizadeh-Hesary, F. ve Otsuka, M. (2017). International Remittances and Poverty Reduction: Evidence from Asian Developing Countries, ADBI Working Paper, No: 759. 